\title{
Learning Management Berbasis Web : Efek pada Proses dan Hasil Belajar
}

\author{
Istiqomah Nugraheni \\ SMP Negeri 27 Surakarta, Kota Surakarta - Provinsi Jawa Tengah \\ Corresponding Author. Email: istiqo.nugraheni@gmail.com
}

\begin{abstract}
The purpose of this research is to improve the process and student learning outcomes through the implementation of Web-based learning management. This research method using descriptive method. The subjects in this study were 30 students of SMP Negeri 27 Surakarta. Data collection techniques using interviews and observations. While the data analysis technique used quantitative and qualitative descriptive analysis. The results showed that at the preliminary study stage, the teacher observed student characteristics and learning conditions to determine appropriate activities. At the implementation stage, the teacher designs the lesson plan, determines learning resources, and carries out Web-based learning activities. At the evaluation stage, the teacher analyzes the increase in student learning outcomes with the impact of Webbased informatics learning outcomes that have been able to improve student learning outcomes.
\end{abstract}

Abstrak: Tujuan dalam penelitian ini adalah untuk meningkatkan proses dan hasil belajar siswa melalui implementasi manajemen pembelajaran berbasis Web. Metode penelitian ini menggunakan metode deskriptif. Subyek dalam penelitian ini adalah siswa sekolah SMP Negeri 27 Surakarta dengan jumlah 30 orang. Teknik pengumpulan data menggunakan wawancara dan observasi. Sedangkan teknik analisis datanya menggunakan analisis deskriptif kuantitatif dan kualitatif. Hasil penelitian menunjukkan bahwa pada tahap studi pendahuluan, guru mengamati karakteristik siswa dan kondisi pembelajaran untuk menentukan kegiatan yang tepat. Pada tahap pelaksanaan, guru merancang RPP, menentukan sumber belajar, dan melaksanakan kegiatan pembelajaran berbasis Web. Pada tahap evaluasi, guru menganalisis peningkatan hasil belajar siswa dengan dampak hasil pembelajaran Informatika berbasis Web telah mampu meningkatkan hasil belajar siswa.
Article History

Received: 04-02-2021

Revised: 10-03-2021

Published: 04-04-2021

\section{Key Words:}

Learning Management, Web, Learning

Outcomes.

\section{Sejarah Artikel}

Diterima: 04-02-2021

Direvisi: 10-03-2021

Diterbitkan: 04-04-2021

\author{
Kata Kunci: \\ Manajemen \\ Pembelajaran, Web, Hasil \\ Belajar.
}

How to Cite: Nugraheni, I. (2021). Learning Management Berbasis Web : Efek pada Proses dan Hasil Belajar. Jurnal Paedagogy, 8(2). doi:https://doi.org/10.33394/jp.v8i2.3489

https://doi.org/10.33394/jp.v8i2.3489

This is an open-access article under the CC-BY-SA License.

\section{Pendahuluan}

Mengajar tidak lagi terbatas pada waktu dan tempat. Dengan teknologi komputer dan komunikasi, guru dan siswa menjadi pembelajar yang tersebar secara spasial dan temporer. Waktu dan batasan fisik ruang kelas tradisional direntangkan ke ruang belajar. Semakin banyak universitas di seluruh dunia sekarang menawarkan program pendidikan virtual. Beberapa perusahaan juga menyediakan pelatihan online untuk karyawan mereka (Khasim dan Khalid, 2016). Pencarian sederhana di Web akan menghasilkan ratusan situs yang menawarkan kursus virtual atau sumber daya untuk mengembangkan dan memberikan kursus tersebut. Pendidikan jarak jauh, kelas virtual, kursus cyber, dan pembelajaran interaktif hanyalah beberapa dari sekian banyak istilah yang digunakan untuk menggambarkan implementasi berbeda dari teknologi ini yang memungkinkan ruang belajar (Ouadoud et., al. 2018). Berbagai metode pembelajaran, misal, Konstruktivis, kolaboratif, dan pengalaman, yang mendukung. Teknologi berbasis web tentu saja merevolusi Pendidikan. 
Perkembangan teknologi informasi beberapa tahun belakangan ini berkembang dengan kecepatan yang sangat tinggi, sehingga dengan perkembangan ini telah mengubah paradigma masyarakat dalam mencari dan mendapatkan informasi, yang tidak lagi terbatas pada informasi surat kabar, audio visual dan elektronik, tetapi juga sumber-sumber informasi lainnya yang salah satu diantaranya melalui jaringan internet. Salah satu bidang yang mendapatkan dampak yang cukup berarti dengan perkembangan teknologi ini adalah bidang pendidikan. Pendidikan pada dasarnya merupakan suatu proses pengembangan potensi individu.

Melalui pendidikan, potensi yang dimiliki oleh individu akan diubah menjadi kompetensi. Kompetensi mencerminkan kemampuan dan kecakapan individu dalam melakukan suatu tugas atau pekerjaan. Tugas pendidik atau pendidik dalam hal ini adalah mefasilitasi anak didik sebagai individu untuk dapat mengembangkan potensi yang dimiliki menjadi kompetensi sesuai dengan cita-citanya (Janson et., al. 2017). Oleh karenanya program pendidikan dan pembelajaran seperti yang berlangsung saat ini harus lebih diarahkan atau lebih berorientasi kepada invidu peserta didik (Marjohan, 2009). Pendidikan merupakan suatu proses komunikasi dan informasi dari pendidik kepada peserta didik yang berisi informasi-informasi pendidikan, yang memiliki unsur-unsur pendidik sebagai sumber informasi, media sebagai sarana penyajian ide, gagasan dan materi pendidikan serta peserta didik itu sendiri (Oetomo dan Priyogutomo, 2004). Beberapa bagian unsur ini mendapatkan sentuhan media teknologi informasi, sehingga mencetuskan lahirnya ide tentang e-learning (Han dan Shin, 2016).

Dalam pembelajaran hal yang perlu diketahui para pendidik antara lain adalah kecerdasan siswa agar dapat menolong kesulitan belajar siswa (Sagala, 2013). Kecerdasan merupakan salah satu faktor utama yang menentukan sukses gagalnya peserta didik belajar di sekolah. Kualitas proses belajar seseorang dipengaruhi oleh berbagai faktor. Menurut Syah (2011), dengan merujuk pada teori belajar kognitif, bahwa fakror-faktor yang mempengaruhi belajar itu dikelompokkan kedalam kategoti yaitu faktor internal, faktor eksternal, dan faktor pendekatan belajar yang digunakan (Darmawan \& Permasih, 2011).

Pendekatan belajar yaitu jenis upaya belajar siswa yang meliputi strategi dan metode yang digunakan siswa untuk melakukan kegiatan mempelajari materi pelajaran. Strategi belajar bagaimana yang digunakan pembelajar ini akan berpengaruh terhadap kualitas belajar (Darmawan \& Permasih, 2011). Pada kenyataannya walau semua pendidik sudah tahu cara melaksanakan proses belajar mengajar yang dituntut oleh kurikulum, tetap saja mereka giat menerapkan metode tradisional atau konvensional. Mencatat, berceramah, menghafal dan murid harus menuruti semua yang dikatakan pendidik. Selain itu, agar nama pendidik dan sekolah tetap harum, siswa dituntut untuk meraih nilai yang tinggi. Kuncinya adalah pembelajaran yang berfokus pada hasil, namun mengabaikan proses. Anak digiring ke dalam suasana kelas yang membosankan. Sejak ada kebijakan yang mengharuskan anak mencapai standar kelulusan, maka semua sekolah berlomba-lomba membuat program untuk menjadikan peserta didiknya lulus seratus persen.

Kendala bagi dunia pendidikan untuk menghasilkan lulusan yang berkualitas adalah masih banyaknya sekolah yang mempunyai pola piker tradisional di dalam menjalankan proses belajarnya yaitu sekolah hanya menekankan pada kemampuan logika (matematika) dan bahasa. Kenyataan menunjukkan bahwa program pendidikan yang berlangsung saat ini lebih banyak dilaksanakan dengan cara membuat generalisasi terhadap potensi dan kemampuan siswa. Hal ini disebabkan karena kurangnya pemahaman pendidik tentang karakteristik individu serta pendekatan pembelajaran yang digunakan kurang tepat, karena 
hanya fokus pada kemampuan kogntif saja dan mengabaikan kemampuan afektif dan psikomotorik siswa

Adanya pemanfaatan teknologi dalam proses pembelajaran adalah melalui pembelajaran berbasis web. Pembelajaran berbasis web merupakan suatu kegiatan pembelajaran yang memanfaatkan media situs (Website) yang bisa diakses melalui jaringan Internet. Pembelajaran berbasis web atau yang dikenal juga dengan "web based learning" merupakan salah satu jenis penerapan dari pembelajaran elektronik atau (e-learning). Teknologi Informasi dan komunikasi seperti komputer, laptop, Netbook serta Handpone sekarang sudah tidak asing lagi bagi siswa, demikian juga dengan Internet. Dengan berbagai kemudahan akses internet dengan perangkat komputer maupun handpone pembelajaran berbasis web dapat dilaksanakan dengan baik. Melalui pembelajaran berbasis web ini pendidik dapat memposting materi, memberikan tugas, mengadakan kuis, memberikan pengayaan, berdiskusi dengan siswa, memberikan berbagai informasi dan lain sebagainya. Pembelajaran pun bisa dilaksanakan dari mana saja kapan saja sehingga lebih mudah dan menyenangkan.

Informatika merupakan salah satu materi mata pelajaran yang ada pada jenjang Sekolah Menengah Pertama (SMP). Dalam penelitian pengembangan ini, peneliti memberikan materi software komputer sebagai pengenalan pada siswa kelas VII yang dilaksanakan dengan aktivitis pembelajaran berbasis web. Selama ini, pembelajaran informatika masih dilaksanakan menggunakan buku paket dan buku Lembar Kerja Siswa (LKS), sedangkan untuk praktikum dilaksanakan di laboratorium komputer. Seiring perkembangan ilmu pengetahuan dan teknologi buku paket dan LKS saja ternyata tidak mampu memberikan berbagai informasi terbaru yang senantiasa berubah sangat cepat. Hingga akhirnya siswa bersama dengan guru menambah dengan melakukan pencarian materi pembelajaran dari sumber internet, dan hasilnya sangat beragam mulai dari artikel, buku elektronik dan lain sebagainya. Antara siswa satu dengan yang lainpun dalam melakukan pencarian ada yang mendapatkan hasil yang sama dan ada juga yang tidak sama, ada sebagian mendapatkan materi yang lengkap ada sebagian lagi mendapatkan materi yang kurang lengkap sehingga tidak optimal. Oleh karena itu diperlukan pengelolaan pembelajaran yang lebih efektif agar pembelajaran dapat dilaksanakan secara optimal. Hasil penelitian yang dilakukan oleh Lam, (2002) menunjukkan bahwa pembelajaran interaktif lebih baik dari pada pembelajaran pasif yang dilihat dari segi proses dan hasilnya.

Pemeriksaan pembelajaran cyber mengungkapkan beberapa kemungkinan aplikasi teknologi Web yang berbeda untuk penciptaan berbagai jenis lingkungan belajar (Khaleel dan Wakim, 2018). Meskipun beberapa web hanya menyampaikan materi pembelajaran tradisional (misal: $m s$ word dan power point), yang lain mengambil keuntungan yang lebih baik dari teknologi hypertext dan kolaborasi (Lin dan Lin 2019). Lingkungan yang berbeda ini jelas tidak sama efektifnya. Apa efek dari berbagai lingkungan belajar berbasis web pada pembelajaran dan kinerja?. Untuk menentukan efektivitas relatif dari lingkungan yang berbeda, pendidik perlu memeriksa strategi pengajaran yang didukung oleh lingkungan sekolah. Lagipula, IT hanyalah pendukung. Yang membuat perbedaan bukanlah teknologi itu sendiri, melainkan metode pembelajaran yang diaktifkan dan didukung oleh teknologi (Le dan T.A.,2019). Dalam penelitian ini, secara empiris mempelajari efektivitas relatif dari pembelajaran Informatika berbasis web, yaitu, pembelajaran secara interaktif. Lebih khusus, lingkungan belajar di mana Web digunakan untuk menyampaikan materi pembelajaran informatika berbasis Web dalam hal proses dan hasil pembelajaran. Dengan kata lain, untuk 
menentukan pembelajaran informatika berbasis Web dan untuk peningkatan dalam proses pembelajaran serta tingkat pengetahuan yang diperoleh oleh peserta didik.

\section{Metode Penelitian}

Penelitian ini menggunakan metode penelitian deskriptif. Subjek dalam penelitian ini adalah siswa kelas VII SMP Negeri 27 Surakarta. Peserta yang digunakan Kelas VII untuk mengasumsikan bahwa semua peserta adalah homogen telah belajar Informatika satu semester agar memenuhi syarat untuk studi ini. Menurut Gay (2000), penelitian tidak membutuhkan banyak peserta. Oleh karena itu, penelitian ini menggunakan sampel yang dapat diakses. Studi ini mengumpulkan informasi dengan menggunakan survei untuk memeriksa efektivitas Learning Management berbasis Web untuk mengajar Informatikan di ruang kelas. Untuk ruang lingkup pengelolaan pembelajaran berbasis web yaitu perencanaan pembelajaran dan pelaksanaan pembelajaran. Teknik pengumpulan data menggunakan wawancara dan observasi. Sedangkan teknik analisis datanya menggunakan analisis deskriptif kuantitatif dan kualitatif.

\section{Hasil Penelitian dan Pembahasan}

\section{Pelaksanaan Pembelajaran Informatika Berbasis Web di Kelas}

Pelaksanaan pembelajaran informatika berbasis web dilaksanakan dalam penelitian ini meliputi 4 tahap, yaitu:

Tahap studi pendahuluan: Pembelajaran informatika berbasis web ini diawali dengan tahap studi pendahuluan. Ada empat langkah pokok di dalam tahap ini yaitu survey lapangan, analisis peserta didik, analisis materi, dan analisis tujuan pembelajaran Berdasarkan silabus SMP pembelajaran informatika diajarkan pada siswa kelas VII, pembelajaran informatika selama ini masih dilaksanakan menggunakan buku paket dan buku Lembar Kerja Siswa (LKS), sedangkan untuk praktikum dilaksanakan di laboratorium komputer. Seiring perkembangan ilmu pengetahuan dan teknologi buku paket dan LKS saja ternyata tidak mampu memberikan berbagai informasi terbaru yang senantiasa berubah sangat cepat. Hingga akhirnya siswa bersama dengan guru menambah dengan melakukanpencarian materi pembelajaran dari sumber internet, dan hasilnya sangat beragam mulai dari artikel, buku elektronik dan lain sebagainya. Antara siswa satu dengan yang lainpun ada yang mendapatkan hasil yang sama dan ada juga yang tidak sama dalam melakukan pencarian, ada sebagian mendapatkan materi yang lengkap ada sebagian lagi mendapatkan materi yang kurang lengkap. Selama ini pembelajaran informatika juga dilakukan melalui media sosial seperti Facebook, Instagram, serta Whatsapp.

Tabel 1. Hạsil Observasi Awal Kegiatan Pembelajaran Informatika di Kelas
\begin{tabular}{|l|l|}
\hline No & \multicolumn{1}{c|}{ Hasil Wawancara } \\
\hline 1 & $\begin{array}{l}\text { Materi pelajaran, latihan, tugas, soal terbatas dari buku } \\
\text { paket dan LKS }\end{array}$ \\
\hline 2 & $\begin{array}{l}\text { Media pembelajaran menggunakan terbatas pada } \\
\text { Komputer di laboratorium komputer sekolah }\end{array}$ \\
\hline 3 & $\begin{array}{l}\text { Pemantauan belajar dan keaktivan siswa oleh orang tua } \\
\text { terbatas kepada guru melalui perolehan nilai serta } \\
\text { bertanya kepada guru melalui Telephone dan WhatApp }\end{array}$ \\
\hline 4 & $\begin{array}{l}\text { Siswa merasa bosan sehingga kurang dapat memahami } \\
\text { materi pembelajaran dengan baik yang mengakibatkan } \\
\text { kompetensi yang dicapai kurang memuaskan }\end{array}$ \\
\hline
\end{tabular}


Berdasarkan tabel 1 diatas menunjukkan bahwa hasil analisa data atau informasi dari kegiatan pembelajaran informatika yang selama ini dilaksanakan secara garis besar berkategori Cukup. Pada pembelajaran Informatika, kualitas proses pembelajaran menunjukkan indikasi rendah. Indikator rendahnya kualitas proses pembelajaran dapat dilihat dari indikator perhatian. Perhatian siswa terhadap pembelajaran rendah. Hal ini terbukti banyak siswa yang mengobrol sendiri atau bahkan tampak bosan dan mengantuk ketika guru menerangkan materi. Hal ini disebabkan karena pengajaran yang diberikan oleh guru hanya berbentuk ceramah dalam menerangkan materi. Dan siswa hanya sebagai pendengar, sehingga hal ini akan membuat siswa bosan.

Tahap pelaksanaan; Tahap pelaksanaan kegiatan pembelajaran meliputi penyusunan RPP dilakukan dengan Perangkat pembelajaran yang dipersiapkan meliputi program tahunan, program semester, perhitungan minggu efektif, silabus dan Rencana Pelaksanaan Pembelajaran (RPP). Pembuatan perangkat pembelajaran dilakukan sebagai langkah awal guru agar kegiatan belajar mengajar berjalan dengan lancar dan sesuai dengan apa yang diinginkan. Penyusunan materi harus memperhatikan memperhatikan hal-hal berikut: (1) Sumber belajar atau media pembelajaran yang dipilih dapat dipakai untuk mencapai tujuan atau kompetensi yang ingin dicapai; (2) Sumber belajar atau media pembelajaran yang dipilih dapat memudahkan pemahaman peserta didik; (3) Sumber belajar atau media pembelajaran dideskripsikan secara spesifik dan sesuai dengan materi pembelajaran; dan (4) Sumber belajar atau media pembelajarann yang dipilih sesuai dengan tingkat perkembangan kognitif, karakteristik afektif, dan keterampilan motorik peserta didik.

Pada tahap awal di tahun 2014-2016 pengembangan google classroom tidak diperuntukan untuk semua orang hanya sekolah yang berkerjasama dengan google, namun di bulan Maret 2017 google classroom dapat diakses oleh seluruh orang dengan menggunakan google pribadi. Hal ini yang dapat dimanfaatkan oleh guru, siswa dan wali murid dalam pembelajaran, sehingga tidak diperlukan kerjasama dengan google. Pemanfaatan secara terbuka dapat memberikan keuntungan bagi pengguna google classroom. Penelitian yang dilakukan oleh Shampa Iftakhar (2016) dengan judul Google Classroom: What Works and How? berisi mengenai bahwa google classroom membantu untuk memonitoring siswa untuk belajar. Guru dapat melihat seluruh aktivitas siswa selama pembelajaran di google classroom. Interaksi antara guru dan siswa terekam dengan baik. Adapun fitur yang dimiliki oleh google classroom menurut Wikipedia (2017): Assigmenments (tugas) Penugasan disimpan dan dinilai pada rangkaian aplikasi produktivitas google yang memungkinkan kolaborasi antara guru dan siswa atau siswa kepada siswa. Dokumen yang ada di google drive siswa dengan guru, file di-host di drive siswa dan kemudian diserahkan untuk penilaian. Guru dapat memilih file yang kemudian dapat diperlakukan sebagai template sehingga setiap siswa dapat mengedit salinannya sendiri dan kemudian kembali ke nilai kelas alih-alih membiarkan semua siswa melihat, menyalin, atau mengedit dokumen yang sama. Siswa juga dapat memilih untuk melampirkan dokumen tambahan dari Drive mereka ke tugas pengumuman, tugas, atau pertanyaan yang ada dari kelas lain. Guru juga dapat berbagi tulisan di beberapa kelas dan kelas arsip untuk kelas masa depan. Pekerjaan siswa, tugas, pertanyaan, nilai, komentar semua dapat diatur oleh satu atau semua kelas, atau diurutkan menurut apa yang perlu dikaji. Adanya

Pertama program blended learning milik Google classroom menggabungkan pembelajaran di dalam kelas dengan latihan di komputer. Laporan belajar yang detil akan membantu pendidik mengikuti kemajuan setiap siswanya. Kegiatan yang berkelanjutan 
membantu pendidik untuk mengatur bahan ajar dan sesi kelas yang sesuai untuk siswa. Salah satu bahan ajar Google Classroom adalah berikut.

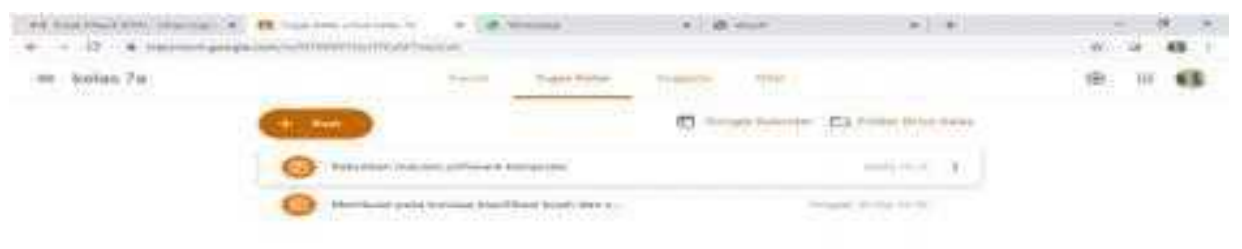

Kedua Interaktif: Siswa menjadi aktif menggunakan program tatapmuka berbasis waktu yang disediakan Google classroom. Dalam suatu pelajaran, murid dapat kembali ke bagian sebelumnya ataupun bagian selanjutnya dan melihat gambar yang jelas yang dapat membantu memahami materi. Ketiga, Cakupan dan Tahapan: Pada pembelajaran berbasis komputer ini, penyajian materi memanfaatkan cara otak manusia terorganisir.

Pelaksanaan pembelajaran: Kegiatan pembelajaran berbasis Web Google classroom di kelas VII A dilaksanakan pada saat kegiatan pembelajaran.

Evaluasi: dalam evaluasi ini dengan melihat hasil belajar baik presentasi untuk diskusi maupun tugas yang diberikan sehingga bisa menjadi tolak ukur dalam penentuan.

\section{Hasil yang Dicapai}

Siswa mulai diperkenalkan dengan media pembelajaran menggunakan google classroom pada subjek ICT. Kemudian siswa mulai membuat akun google classroom dan mendaftar ke google classroom. Adapun perbandingan nilai UH sebelum dan setelah pembelajaran berbasis Web dengan Google classroom diketahui dari tabel 2 berikut ini.

Tabel 2. Perbandingan Pembelajaran Informatika dan Pembelajaran Informatika Berbasis Web

\begin{tabular}{|c|l|l|}
\hline No & \multicolumn{2}{|c|}{ Pembelajaran } \\
\cline { 2 - 4 } & $\begin{array}{l}\text { Informatika } \\
\text { Materi pelajaran, latihan, tugas, soal } \\
\text { terbatas dari buku paket dan LKS. }\end{array}$ & $\begin{array}{l}\text { Materi pelajaran, latihan, tugas, } \\
\text { soal dari buku paket, LKS dan dari } \\
\text { google classroom }\end{array}$ \\
\hline 2 & $\begin{array}{l}\text { Media pembelajaran menggunakan } \\
\text { terbatas pada komputer di } \\
\text { laboratorium komputer sekolah }\end{array}$ & $\begin{array}{l}\text { Media pembelajaran menggunakan } \\
\text { Komputer di laboratorium } \\
\text { komputer sekolah komputer di } \\
\text { rumah atau warnet serta Hand } \\
\text { Phone }\end{array}$ \\
\hline 3 & $\begin{array}{l}\text { Pemantauan belajar dan keaktivan } \\
\text { siswa oleh orang tua terbatas kepada } \\
\text { guru melalui perolehan nilai serta } \\
\text { bertanya kepada guru melalui } \\
\text { Telephone dan WhatApp }\end{array}$ & $\begin{array}{l}\text { Orang tua dapat memantau } \\
\text { perkembangan putra putrinya } \\
\text { apalagi bagi orang tua dan siswa } \\
\text { yang tidak tinggal dalam satu } \\
\text { rumah bisa melakukan pemantauan } \\
\text { dari mana saja dan kapan saja. }\end{array}$ \\
\hline 4 & $\begin{array}{l}\text { Siswa merasa bosan sehingga kurang } \\
\text { dapat memahami materi pembelajaran }\end{array}$ & $\begin{array}{l}\text { Siswa merasa senang sehingga } \\
\text { siswa dapat memahami materi }\end{array}$ \\
\hline
\end{tabular}




\begin{tabular}{|l|l|}
$\begin{array}{l}\text { dengan baik yang mengakibatkan } \\
\text { kompetensi yang dicapai kurang } \\
\text { memuaskan }\end{array}$ & $\begin{array}{l}\text { pembelajaran dengan baik sehingga } \\
\text { kompetensi pembelajaran dapat } \\
\text { dicapai dengan sangat baik }\end{array}$ \\
\hline
\end{tabular}
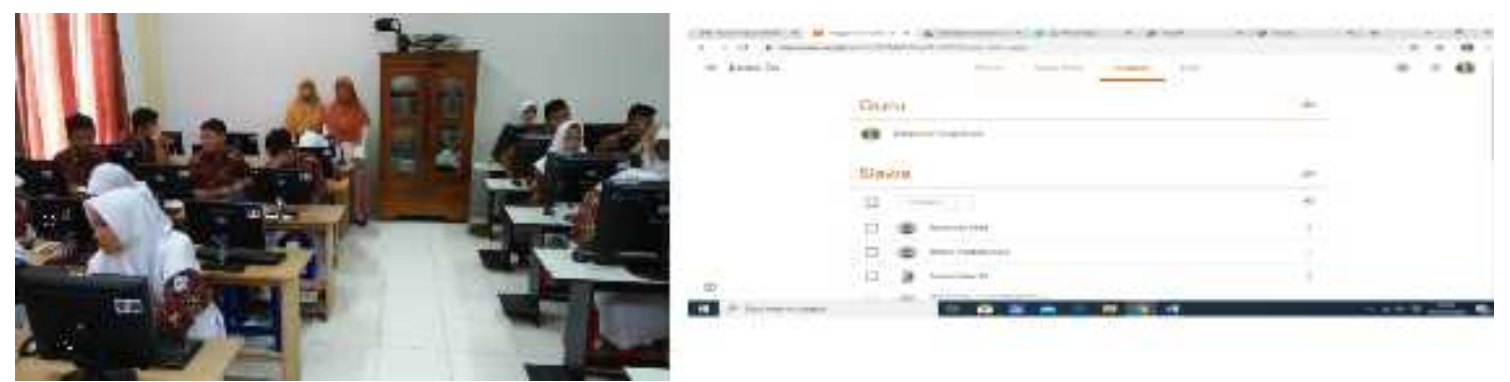

Gambar 1: Pembalajran di Lab computer dengan Google Classroom

Tabel 2 tersebut diatas menunjukkan perbandingan pembelajaran Informatika yang dilaksanakan selama ini dengan pembelajaran Informatika berbasis web. Dari hasil perkembangan dari awal pembelajaran Informatika yang telah dilaksanakan selama ini dengan pembelajaran Informatika berbasis web menunjukkan peningkatan yang sangat baik

Tabel 3. Perbandingan Nilai Awal dan Nilai Setelah Google classroom

\begin{tabular}{|c|l|c|c|}
\hline No & \multicolumn{1}{|c|}{ Aspek } & Nilai Awal & Setelah Google classroom \\
\hline 1 & Nilai terendah & 40 & 55 \\
\hline 2 & Nilai tertinggi & 70 & 100 \\
\hline 3 & Rata-rata & 56 & 74 \\
\hline 4 & KKM & 65 & 65 \\
\hline 5 & Tuntas & 17 siswa $(56,7 \%)$ & 27 siswa $(90 \%)$ \\
\hline 6 & Tidak Tuntas & 13 siswa $(43,3 \%)$ & 3 siswa $(10 \%)$ \\
\hline
\end{tabular}

\section{Ketuntasan}

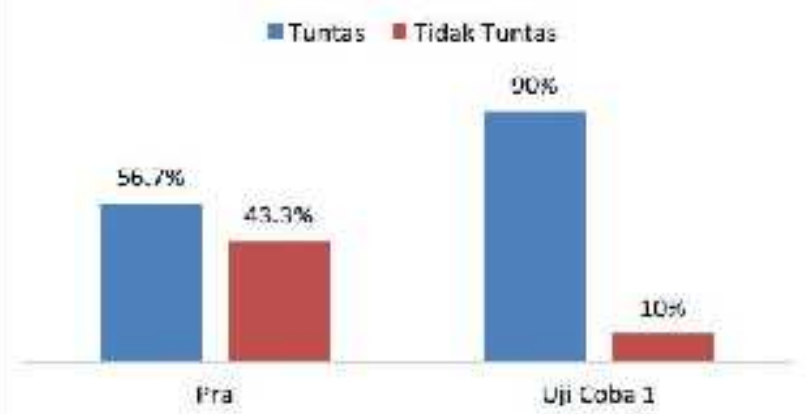

Berdasarkan Tabel 3 diatas menunjukkan pencapaian hasil Ulangan Harian dari pembelajaran Informatika yang selama ini dilaksanakan dengan pencapaian Ulangan Harian dari pembelajaran Informatika berbasis web terdapat perkembangan dan peningkatan pencapaian nilai yang sangat baik. Pembelajaran Informatika berbasis web di SMP Negeri 27 Surakarta 
mampu meningkatkan hasil belajar siswa. Pada kondisi awal sebelum ujicoba I produk pembelajaran Informatika berbasis web, nilai terendah 40, nilai tertinggi 70, nilai rata-rata 56. Jumlah siswa yang tuntas KKM adalah 17 siswa atau 56.7\% dari 30 siswa kelas VII A. Setelah pembelajaran Informatika berbasis web, nilai terendah 55, nilai tertinggi 100, nilai rata-rata 74. Jumlah siswa yang tuntas KKM adalah 27 siswa atau 90\% dari 30 siswa kelas VII A. Sehingga hasil pembelajaran Informatika berbasis web di kelas VII SMP Negeri 27 Surakarta dilihat dari hasil belajar yang dicapai berkategori sangat baik dan layak digunakan.

Proses pembelajaran Informatika berbasis web dilaksanakan dengan penuh kesungguhan baik oleh guru maupun siswa, dengan harapan pembelajaran bermakna dapat terwujud dengan efektif dan efisien. Siswa dapat memahami materi pelajaran dengan baik sehingga hasil belajar siswa mencapai hasil memuaskan. Terdapat kesamaan penelitian siatas dengan beberapa penelitian terdahulu diantarana adalah penelitian oleh Montelpare dan Williams (2010), penelitian Cholid, dkk. (2016), penelitian Halidi, dkk. (2015) yang semua penelitian terdahulu tersebut meneliti tentang media pembelajaran berbasis web. Secara garis besar menyatakan bahwa media pembelajaran berbasis web yang telah dikembangkan memiliki nilai kepraktisan, kebermanfaatan, kesesuaian, kemenarikan dan memiliki tingkat kemudahan dalam mengoperasikan dalam menunjang kegiatan belajar siswa yang efektif dan efisien.

\section{Kesimpulan}

Berdasarkan hasil penelitian ini, dapat disimpulkan sebagai berikut: Pelaksanaan pembelajaran informatika berbasis web di kelas VII SMP Negeri 27 Surakarta meliputi 4 tahap, yaitu: (1) tahap studi pendahuluan; (2) tahap pelaksanaan; dan (4) evaluasi. Pada tahap studi pendahuluan, guru mengamati karakteristik siswa dan kondisi pembelajaran untuk menentukan kegiatan yang tepat. Pada pelaksanaan, guru merancang RPP, menentukan sumber belajar, dan melaksanakan kegiatan pembelajaran berbasis web. Pada evaluasi, guru menganalisis peningkatan hasil belajar siswa. Dampak pembelajaran informatika berbasis web di kelas VII SMP Negeri 27 Surakarta adalah bahwa pencapaian hasil Ulangan Harian pembelajaran Informatika yang selama ini dilaksanakan dengan pencapaian Ulangan Harian pembelajaran Informatika berbasis web terdapat perkembangan dan peningkatan pencapaian nilai yang sangat baik. Pembelajaran Informatika berbasis web telah mampu meningkatkan hasil belajar siswa.

\section{Saran}

Adapun saran yang dapat disampaikan berdasarkan hasil penelitian ini ditujukan kepada guru dan siswa untuk memanfaatkan pembelajaran informatika berbasis web, hendaknya guru memberikan motivasi yang mendorong para siswa untuk selalu belajar sehingga guru selalu mengembangkan dirinya dengan egiatan bersifat improvement untuk para siswa sehingga kompetensi ICT mereka terus berkembang, dan mengkat hasil pembelajaran untuk siswa.

\section{Daftar Pustaka}

A. Janson, M. Söllner, and J. M. Leimeister. (2017). "Individual appropriation of learning management systems-antecedents and consequences," AIS Transactions on Human-Computer Interaction, vol. 9(3), pp. 173-201,

Cholid, Angga Achmad, Elmunsyah, Hakkun, Patmanthara, Syaad Patmanthara. (2016). "Rancangan Pengembangan Web Based Learning Mata Pelajaran Jaringan Dasar 
Paket Keahlian TKJ Pada SMKN Se Kota Malang”. Seminar Nasional Pendidikan (SNP). ISSN: $2503-4855$

Darmawan, Deni. \& Permasih. (2011). Kurikulum dan Pembelajaran. Jakarta: Raja Grafindo.

Halidi, H. M., Husain, S. N., \& Saehana, S. (2015). Pengaruh media pembelajaran berbasis TIK terhadap motivasi dan hasil belajar IPA siswa kelas V SDN Model Terpadu Madani Palu. Mitra Sains, 3(1), 53-60.

I. Han and W. S. Shin. (2016). "The use of a mobile learning management system and academic achievement of online students," Computers \& Education, vol. 102, pp. 79-89.

J. W. Lin and H. C. K. Lin. (2019). "User acceptance in a computer-supported collaborative learning (CSCL) environment with social network awareness (SNA) support," Australasian Journal of Educational Technology, vol. 35(1), pp. 100-115.

Lam, Mohamed Khalifa and Rinky. (2002). Web-Based Learning: Effects on Learning Process and Outcome. IEEE TRANSACTIONS ON EDUCATION, VOL. 45, NO. 4

M. Ouadoud, M. Y. Chkouri, and A. Nejjari. (2018). "Learning management system and the underlying learning theories: towards a new modeling of an LMS," International Journal of Information Science and Technology, vol. 2(1), pp. 25-33, .

Marjohan. (2009). School Healing. Yogyakarta: Pustaka Insan Madani.

Mershad, Khaleel dan Wakim, Pilar. (2018). A Learning Management System Enhanced with Intern et of Things Applications. Journal of Education and Learning; Vol. 7, No. 3

N. M. Kasim and F. Khalid. (2016). "Choosing the right learning management system (LMS) for the higher education institution context: a systematic review," International Journal of Emerging Technologies in Learning, vol. 11 (06), pp. 55-61,.

Oetomo, B. S. D dan Jarot Priyogutomo. (2004). Kajian Terhadap Model e-Media dalam Pembangunan Sistem e-Education. Makalah Seminar Nasional Informarika di Universitas Ahmad Dahlan Yogyakarta pada 21 Februari 2004

R. Harandi. (2015). "Effects of e-learning on Students' Motivation," Procedia-Social and Behavioral Sciences, vol. 181, pp. 423-430,

S. Liaw. (2008). "Investigating students' perceived satisfaction, behavioral intention, and effectiveness of e-learning: A case study of the Blackboard system," Computers \& education, vol. 51(2), pp. 864-873.

Q. Le and T. T. A. Do. (2019). "Active Teaching Techniques for Engineering Students to Ensure the Learning Outcomes of Training Programs by CDIO Approach," International Journal on Advanced Science, Engineering and Information Technology, vol. 9(1), pp. 266-273.

Y. C. Chen, R. H. Hwang, and C. Y. Wang. (2012). "Development and evaluation of a Web 2.0 annotation system as a learning tool in an e-learning environment," Computers \& Education, vol. 58(4), pp. 1094-1105. 